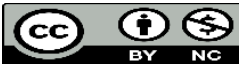

Licenciado sob uma licença Creative Commons

ISSN 2175-6058

http://dx.doi.org/10.18759/rdgf.v19i3.1663

\title{
OS DESAFIOS DO CONTROLE SOCIAL NO SISTEMA DE JUSTIÇA BRASILEIRO
}

\section{CHALLENGES FOR SOCIAL ACCOUNTABILITY OF THE BRAZILIAN SYSTEM OF JUSTICE}

\author{
Jorge Machado \\ Gisele Craveiro \\ Ester Rizzi
}

\section{RESUMO}

As tecnologias de informação e comunicação podem potencializar a transparência, participação e o controle externo do Sistema de Justiça. Para que isso ocorra, são condições necessárias que os cidadãos tenham fácil acesso às informações públicas e que se incorporem mecanismos digitais de participação social. No entanto, a disponibilização dos dados por parte do Poder Judiciário e de outras instituições do Sistema de Justiça brasileiro, tomadas como requisito básico, é apenas satisfatória como revelam alguns estudos, não garantindo accountability. 0 objetivo desse texto é fazer uma análise dos avanços e desafios para o aprimoramento da participação e do controle social sobre o Sistema de Justiça do Brasil.

Palavras-chave: Accountability. Sistema de Justiça. Tecnologias da Informação e Comunicação (TICs).

\section{ABSTRACT}

The information and communication technologies can potentialize transparency, participation and social accountability in the system of justice. The 
necessary conditions to effect this potential are easy access to public sector information and digital channels for social participation. Nevertheless, data disclosure to society by Brazilian Judiciary and other institutions of the System of Justice, considered as fundamental requirement, is only suitable according to some research works, which does not assure accountability. The objective of this text is to analyze the advances and challenges for the improvement of social participation and accountability in the Brazilian System of Justice.

Keywords: Accountability. Brazilian system of justice. Information and Communication Technologies (ICT).

\section{INTRODUÇÃo}

Desde a Constituição de 1988, as instituições do Sistema de Justiça - Ministério Público, Defensoria Pública e o próprio Poder Judiciário tiveram suas competências ampliadas. A partir do fortalecimento de instituições que ingressam com ações judiciais, também os juízes e tribunais passaram a receber mais ações de diferentes temáticas e de maior importância política. Muitos autores descrevem esse processo como "judicialização da política" ou "politização do Judiciário". Quase que um pressuposto desses conceitos, está implícita uma crítica. A observação de que o Judiciário estaria desequilibrado, atuando onde deveria haver ação prioritária de outros poderes.

Mais recentemente, porém, constatou-se que a maior influência do Judiciário - e das outras instituições do Sistema de Justiça - decorre do próprio desenho institucional estabelecido na Constituição Brasileira de 1988. Seja qual for a corrente de análise sobre o fenômeno da participação das instituições do Sistema de Justiça na política, todos concordam que o papel político do Judiciário foi reforçado a partir de 1988. Recentemente, sua atuação foi fundamental em ações envolvendo políticos de alto escalão, como foram os casos do mensalão e da operação Lava-Jato. Por outro lado, houve avanços em temas de grande importância e repercussão social, como união civil de pessoas do mesmo sexo, aborto de fetos anencéfalos e cotas raciais para acesso a universidades públicas, apenas para citar três decisões importantes que foram decididas pelo Supremo Tribunal Federal. 
Dado o inegável aumento de atuação política e social dos órgãos do Sistema de Justiça, torna-se imperativa a necessidade de aprimoramento da transparência e do accountability das instituições vinculadas a esse Sistema. Em tese, juízes, promotores, defensores e procuradores gozam de autonomia necessária para o exercício de suas funções, razão pela qual a simples ideia de promover a participação e o controle social sobre o Sistema de Justiça já suscita resistências e preocupações - como demonstram as entrevistas no estudo "Os Desafios da Transparência no Sistema de Justiça", realizado no âmbito do edital "Pensando o Direito", do Ministério da Justiça (CRAVEIRO, MACHADO, et. al, 2013).

0 objetivo desse ensaio é de, quatro anos após o referido estudo, fazer uma análise dos avanços e desafios para o aprimoramento da participação e do controle social sobre o Sistema de Justiça do Brasil. Na primeira parte do ensaio, discutimos a importância que a participação social nas instituições jurídicas assume para a construção da democracia e da legitimidade democrática dessas mesmas instituições. Em seguida, foram analisadas algumas das estratégias já existentes de abertura de dados e participação em instituições do Sistema de Justiça. Por fim, identificamos insuficiências e caminhos para o aumento da transparência de dados, para o uso intensivo das tecnologias como canais de participação. A pergunta que se quer responder é: como aprofundar o processo já iniciado de ampliação do acesso à informação das instituições do Sistema de Justiça, como intensificar a participação e o controle social e, por fim, qual papel a tecnologia já desempenha e pode desempenhar nesses processos.

\section{POR QUE PARTICIPAÇÃO E CONTROLE SOCIAL NO SISTEMA DE JUSTIÇA?}

Numa democracia republicana, a ideia de cidadania está estreitamente relacionada à possibilidade de os cidadãos e cidadãs participarem do estabelecimento das regras do jogo. Dada complexidade da sociedade, tornou necessário a criação de instituições de representação e de mediação, assim como de uma burocracia especializada - no sentido weberiano - que gestionasse esse poder republicano, em cuja base se 
assenta na cidadania. Nesse sentido, se faz igualmente necessário também fiscalizar aqueles que agem em nome desse poder que lhe é delegado.

A Constituição Brasileira de 1988, em seu artigo 1ํ, Parágrafo Único estabelece que "Todo o poder emana do povo, que o exerce por meio de representantes eleitos ou diretamente, nos termos desta Constituição". Maria Victoria Benevides (1991) afirma, a partir desse parágrafo e do desenho institucional da participação na Constituição, que vivemos em uma democracia semi-direta. Isso significa que as cidadãs e os cidadãos exercem o poder por meio de representantes mas também diretamente. Plebiscitos, referendos, audiências públicas, fiscalização e acompanhamento da atividade estatal são intrínsecos à nossa Democracia. Não delegamos simplesmente o exercício do poder. Nossa Democracia exige participação direta, constante e fiscalizatória da atuação do Estado brasileiro, o que inclui todos os entes federados e os três poderes.

Segundo Smith (2002), a ideia moderna de cidadania possui grande relação com participação política, mesmo essa sendo feita através de sistemas de representação política à distância, como a Democracia Representativa. Numa perspectiva republicana, o exercício da cidadania é visto como um elemento positivo para o fortalecimento da democracia, que tende a se tornar mais legítima e a refletir mais adequadamente os interesses coletivos

Para que a participação e o controle social ocorram, é condição necessária que os cidadãos tenham acesso às informações públicas das Políticas e dos órgãos de que queiram participar. Não existe possibilidade de participação e controle social se houver uma assimetria de informações entre aqueles que exercem o poder diretamente e aqueles que acompanham a política pública ou instituição.

Aqui entram as tecnologias de informação e comunicação, que potencializaram significativamente essa capacidade de controle social. É certo que esse termo tem sentido ambíguo. O controle social pode ser compreendido como o controle do Estado sobre seus cidadãos; ou, no sentido sociológico, da própria sociedade sobre os indivíduos, no sentido moral, comportamental e ideológico. Nessa perspectiva, é visto como algo bastante negativo, se opondo à ideia de liberdade 
e autonomia. Mas o controle social, na linguagem da gestão pública, traduz a participação do cidadão e das organizações da sociedade civil na formulação, implementação, no monitoramento e na fiscalização das ações do poder público e no acompanhamento de execução de políticas governamentais. Na prática, esse controle social se refere ao exercício da capacidade fiscalizadora do cidadão sobre aqueles a quem delegaram, direta ou indiretamente, o poder. Assim, o controle social recai sobre o uso de recursos públicos de qualquer espécie ou do exercício das funções públicas. Isso se traduz pelo controle sobre o emprego de recursos orçamentários, patrimoniais, de pessoal, de processos de tomada de decisões e do correto cumprimento da gestão pública por parte de servidores.

Na prática, o controle social pode se dar de várias formas: através da solicitação de informações diretas ou via eSIC (Sistema Eletrônico de Informação ao Cidadão), do comparecimento em audiências públicas, da participação em conferências nacionais que definem metas de longo prazo, do monitoramento da execução orçamentária do município ou órgão, de reclamações e sugestões por meio de canais institucionais como os SACs (Serviço de Atendimento ao Cidadão) e Ouvidorias, da visita a gabinetes de vereadores e deputados, da participação em conselhos de Políticas Públicas, entre outros meios.

\section{O CONTROLE SOCIAL NO JUDICIÁRIO E OUTRAS INSTITUIÇÕES}

Pela natureza do trabalho dos juízes, o controle social pode ser visto como uma forma de cerceamento, pressão ou ameaça à autonomia. Há uma grande discussão na teoria do direito acerca dos limites da atividade jurisdicional e sua interação com o contexto social e político de suas decisões. Na visão tradicional, o juiz deveria promover julgamentos livre de pressões, seguindo a lei e a sua consciência. Para que a sociedade não fique à mercê de decisões que, no fundo, são decisões de seres humanos falíveis, o juiz deve expor suas razões e fundamentar jurídica e adequadamente suas decisões, sob pena de nulidade (art. 93, IX CF e art. 
489 do novo CPC). Na apresentação de lançamento do trabalho "Desafios da Transparência no Sistema de Justiça" no Ministério da Justiça, nas entrevistas e em outras apresentações, o desconforto com a menção à necessidade de maior controle social era visível. A independência dos juízes parece ser, a priori, uma das condições para a existência do Estado de Direito. Assim sendo, falar em controle social é discorrer sobre algo de difícil compreensão, uma vez que se trata de um conceito pouco presente na cultura jurídica.

A independência funcional está assegurada aos membros da Defensoria Pública (art.134 CF) e do Ministério Público (art.127 CF). Aos Magistrados, estão previstas as garantias do artigo 95 CF (vitaliciedade, inamovibilidade e irredutibilidade de vencimentos), que deveriam garantir na prática sua independência frente à hierarquia administrativa do próprio Poder Judiciário e dos outros poderes. No entanto, a prática da magistratura não é assim tão independente. O Poder Judiciário tem uma organização institucional absolutamente hierarquizada e procedimentos de promoção e remoção com critérios pouco claros que afrontam o princípio da independência do juiz singular (Semer, 2018). Tais características estimulam seus membros a reproduzirem entendimentos e jurisprudências já consolidados, dificultando mudanças interpretativas ou entendimentos diversos a respeito de textos normativos. A homogeneidade jurisprudencial também decorre do fato de haver - ao contrário da sociedade brasileira - elevada homogeneidade de origem social e econômica entre os membros da magistratura: tanto a forma como as exigências dos concursos não são pensados para garantir a pluralidade dos membros. Somam-se a essas características a baixa permeabilidade do Poder Judiciário ao controle social e chegamos ao Poder com baixa legitimidade democrática que conhecemos no Brasil.

Mesmo assim, há avanços nesse sentido em algumas instituições do Sistema de Justiça: a bem-sucedida experiência da Ouvidoria Externa da Defensoria Pública do Estado de São Paulo, que inspirou a determinação hoje válida para todas as defensorias do território nacional. A Lei Complementar n. 80/1994 instituiu, em seu artigo 105B (incluído em mudança de 2009), que "O Ouvidor-Geral será escolhido pelo Conselho Superior, dentre cidadãos de reputação ilibada, não integrante da 
Carreira, indicados em lista tríplice formada pela sociedade civil, para mandato de 2 (dois) anos, permitida 1 (uma) recondução". Ouvidorias Externas - compostas por pessoas que não compõem a carreira que será objeto das escutas - em todos os órgãos do Sistema de Justiça seriam boa medida para aumentar a interlocução entre aqueles que decidem as prioridades de órgãos públicos e, no caso do Poder Judiciário, exercem o poder e aqueles que a ele se submetem.

As audiências públicas e a possibilidade de participação de amici curiae frequentes em diversas ações judiciais que tratam de temas socialmente sensíveis no Supremo Tribunal Federal - e ainda de forma experimental em outras instâncias do Judiciário - são outra possibilidade de participação social neste Poder que é o que conta com menos legitimação social.

Além dos diferentes canais de participação já citados, as tecnologias de informação possibilitam hoje um controle maior a partir dos dados que são gerados e disponibilizados pelo próprio Judiciário em seus sítios na internet. No entanto, a disponibilização dos dados não garante o accountability. Conforme Fox (2007), em seu artigo The Uncertain Relationship between Transparency and Accountability, a mera divulgação de informações pode não revelar como as instituições realmente se comportam. Ou ainda, os dados podem não ser suficientemente claros ou compreensíveis ao público. Assim, a disseminação de informações não leva automaticamente ao accountabilty nem à possibilidade de ação efetiva do cidadão para transformar a orientação institucional. Se o acesso à informação tem o objetivo de garantir as sanções exigidas num sistema de accountability, tanto o setor público, como os atores da sociedade civil, devem possuir mecanismos para garantir isso. Esse tipo de transparência, que não revela como as instituições funcionam e não garante o accountability, é aquela que Fox chama de "transparência opaca" (FOX, 2007; 13). Muito mais associada a disponibilização de dados, mas que carece ainda de mecanismos efetivos de que garantam o accountability. Nesse sentido, em muitos casos a transparência do Sistema de Justiça do Brasil pode ser definida como ainda opaca.

Mecanismos de transparência ativa, como publicação de dados referentes a sentenças e estatísticas de sobre processos arquivados, 
resolvidos e pendentes, recursos físicos e materiais, informações sobre recursos humanos, orçamento, salários, licitações e contratos; e passiva, como uma adequada implementação da Lei de Acesso à Informação (LAI - Lei n.12.527/2011), são, portanto, importantes porém não suficientes. No que se refere à transparência ativa, itens considerados fundamentais para padrões para a transparência, como a divulgação da agenda de audiências marcadas e as efetivamente realizadas com juízes e informações patrimoniais - tais como as declaração de bens que políticos são obrigados a disponibilizar - sequer são cumpridos.

Além desses, é preciso ampliar o acesso à informação da forma como o Poder Judiciário se organiza administrativamente, como organiza seus membros no território e nas áreas de atuação, quais são os critérios de promoção na carreira e aos cargos mais altos dos tribunais, por exemplo. No conjunto dos dados que possui o Judiciário, o foco a transparência tem sido o acesso digital a decisões, informações sobre pessoal, licitações e contratos e dados orçamentários. Um recente avanço foi a Portaria do CNJ no 63 de 17/08/2017, que estabelece padrões para publicação de dados sobre estrutura e pagamento remuneratório de magistrados pelos Tribunais do país, de modo atender a LAI. No entanto, dados que podem denunciar o mau funcionamento do Judiciário, como relatórios de auditorias realizadas e informações sobre investigações e processos disciplinares contra juízes dificilmente estão acessíveis ao público. Da mesma forma, a publicação da lista dos documentos que foram classificados com grau de sigilo, com informações sobre período e razão de sigilo, conforme determina a LAI, não é publicada ou não é localizável nos sítios dos tribunais superiores como STF e STJ.

No que se refere especificamente à transparência ativa, a análise comparativa entre órgãos superiores do sistema de Justiça brasileiro demonstrou ser ainda insatisfatória a publicação de informação judicial e a prestação de serviços eletrônicos a ela associada. Apenas um órgão (CNMP) atendeu a mais de dois terços dos itens analisados em nossa avaliação - baseado na aplicação detalhada no IAcc, Índice de Acessibilidade a Informação Judicial na Internet, criado pelo CEJA, Centro de Estudos Jurídicos das Américas, ligado à OEA, Organização dos Estados Americanos - (Craveiro, Machado et. al, 2017: 89-90). Cabe dizer que no 
estudo do CEJA de 2012 o Brasil que cumpria 72\% dos quesitos do IAcc, posicionando o país em $3^{\circ}$ lugar entre os 33 avaliados naquele ano. No último relatório 2017 do CEJA, o Judiciário brasileiro estava atendendo apenas $46 \%$ dos itens do IAcc, caindo 11 posições no continente em cinco anos ${ }^{1}$. Com relação ao Ministério Público, o IAcc aponta queda também do Brasil no mesmo período, da $3^{\mathrm{a}}$ para a $12^{\mathrm{a}}$ posição, de um índice de 72\% a 42\% (CEJA, 2018; id., 2013).

Embora os dados sobre os cinco tribunais superiores (STF, STJ, TSE, TST, STM) não tenham sido atualizados, num levantamento preliminar feito por estes pesquisadores em seus sítios da web, observa-se que os indicadores de transparência ativa são apenas satisfatórios nos mesmos tribunais. Itens como publicação de recursos físicos, materiais e humanos, agenda de audiências ainda carecem de maior detalhamento. São ainda deficientes as informações salariais e inexistentes as informações sobre patrimônios de autoridades e juízes.

\section{APRIMORAMENTO DO CONTROLE SOCIAL NO SISTEMA DE JUSTIÇA}

As conversas com informantes e as entrevistas realizadas com diferentes atores no estudo de 2013-4 (CRAVEIRO, MACHADO et. al, 2017) já indicavam uma série de medidas que poderiam melhorar o grau de accountability do Sistema de Justiça. O acompanhamento do funcionamento dos fóruns locais, com atividades como visita de escolas, associações locais, poderiam promover uma aproximação de juízes à realidade da comunidade - com seus desafios, demandas e potenciais. Modificar a forma como se dá a seleção de novos juízes - privilegiando a diversidade, com políticas de cotas para negros e mulheres, por exemplo, além de modificar a estratégia conteudista dos concursos públicos - seria outro caminho. Também a necessidade de formação inicial e continuada de juízes foi bastante citada no referido estudo. As escolas de magistratura têm um importante papel na promoção de um Judiciário mais aberto à população. A criação de um conselho de Políticas Públicas - tal como os existentes nas áreas de saúde, educação, segurança - junto às justiças 
estaduais parece que poderia representar um avanço muito grande na abertura do judiciário.

No plano mais amplo, cujas decisões afetam os próprios rumos da democracia, como a escolha de juízes para os tribunais estaduais, regionais e superiores, a participação social teria um importante papel como mecanismo de equilíbrio e controle para que a escolha de juízes não fique apenas no arbítrio político ou forma de controle do conteúdo das decisões dos magistrados de primeira instância, senão que seja um processo que inclua um número mais amplo de atores. Segundo o disposto no artigo 101 da Constituição Federal, o processo de escolha de Ministros para o Supremo Tribunal Federal é de prerrogativa do Presidente da República. Do indicado exige-se, além da aprovação em sabatina no Senado Federal, idade entre "trinta e cinco e menos de sessenta e cinco anos de idade, de notável saber jurídico e reputação ilibada". A necessidade de aperfeiçoamento democrático no processo de indicação de ministros do STF é apenas o exemplo mais eloquente de uma necessidade que perpassa todo o Poder Judiciário: definir quais são os critérios e quais são as possibilidades de participação da sociedade nos procedimentos que levam à progressão da carreira da magistratura e no acesso de membros aos tribunais estaduais, regionais e superiores. Antes da participação direta de outros atores, apenas a garantia de maior transparência de critérios já seria um importante ganho democrático.

Isso demanda especial atenção no processo de escolha de membros para o tribunais superiores. Se fosse um processo que envolvesse vários atores (multistakeholder), seria mais difícil enviesamentos nas decisões. Apesar de ser baseada em atos administrativos, a transparência na indicação de juízes para o STF, por exemplo, é quase nula. Não existem mecanismos que garantam a participação da sociedade civil ou ao menos uma pluralidade maior na escolha. 0 processo no âmbito do Executivo não possui nenhum grau de transparência, não possuindo nenhum registro enquanto ato administrativo, como se demonstrou nos pedidos de informação feitos na pesquisa de Craveiro, Machado et al. (2017, p. 67 A 73). A indicação de Ministros para o STF deveria incluir diversos passos e mecanismos de checks and balances, que dificultassem a criação de laços políticos entre o Chefe do Executivo e ministros do Supremo. 
Como as tratativas para a indicação são feitas de forma secreta e não documentada, a única arguição ao candidato é feita pelo Senado Federal, numa sessão que, na prática, acaba sendo meramente protocolar. Na história da República, apenas Floriano Peixoto teve indicações ao Supremo rejeitadas, entre 1891 e 1894. E isso ocorreu num contexto específico, em que assumia a presidência após a renúncia de Deodoro da Fonseca e num momento em que sua legitimidade era questionada. Desde então, nenhum indicado pelos mais de trinta e cinco presidentes foi rejeitado.

Algumas medidas poderiam reduzir o problema da opacidade do processo de indicação, como a criação de uma comissão mista, formada por representantes dos diferentes órgãos que compõem a cúpula do Judiciário, assim como da Câmara dos Deputados, Senado, Presidência da República e Organizações da Sociedade Civil de reconhecida atuação no campo dos direitos, ou seja, com a adoção de um modelo multistakeholder - aos moldes do Conselho Gestor da Internet ou do Grupo Assessor da Parceria para o Governo Aberto. Esse "comitê de busca" tornaria o processo muito mais inclusivo e legítimo junto aos diferentes setores e grupos de interesse da sociedade, tirando a escolha do mero cálculo político baseado em negociações secretas. Além da comissão mista, também o fim da vitaliciedade para membros de tribunais superiores e a definição de um mandato razoável para os ministros, entre 6 a 10 anos, seria modificações que ampliariam a dinâmica e a participação social na cúpula do Poder Judiciário. No Senado tramita a PEC 44/2012, que propõe a escolha de uma lista tríplice de candidatos a ser submetida ao presidente da República e um mandato de 10 anos para o cargo de ministro do $\mathrm{STF}^{2}$, o que mostra que o horizonte de modificação institucional já foi formulado no âmbito do Poder Legislativo, ainda sem força política para se efetivar.

O potencial de abertura do Sistema de Justiça é muito grande, se considerarmos a possibilidade de uso das Tecnologias da informação e comunicação, TICs. Medidas relativamente simples, como consultas Online através de portais, a abertura de fóruns públicos, enquetes e outros canais de participação social poderiam contribuir para a necessária aproximação do Sistema de Justiça junto à população. Para ficar apenas no âmbito federal, o Executivo possui o Portal Participa.br ${ }^{3}$, onde são 
disponibilizados documentos, colhem-se opiniões, são disponibilizados textos de documentos que recebem críticas e contribuições e ainda se realizam processos deliberativos para priorização de propostas. No Legislativo, há os portais E-democracia ${ }^{4}$, que permitem ver agenda de audiências, participar em debates e até, informalmente, sugerir a inclusão de projetos na pauta do plenário da Câmara dos Deputados. No Portal E-democracia há ainda o Wikilegis ${ }^{5}$, permite comentar artigos de projetos de lei e sugerir propostas de redação, que por sua vez serão avaliados pelo relator do Projeto de Lei. Já o Senado, possui o e-Cidadania ${ }^{6}$, que permite ao cidadão propor informalmente leis, participar de debates e opinar sobre projetos de lei em tramitação. É fato que ainda não há indicadores sobre quanto esses mecanismos de abertura à participação têm impacto efetivo sobre as prioridades e ações políticas dos representantes eleitos. A simples existência de canais que possibilitem a participação, porém, já deve ser saudada.

No Senado foi criado ainda o Índice de Transparência do Poder Legislativo (ITL) ${ }^{7}$, métrica formada por um conjunto de indicadores multidimensionais divido por categorias "Transparência Legislativa", "Transparência Administrativa", "Participação e Controle Social" e "Aderência à LAI". Esse índice visa fomentar a transparência dos órgãos legislativos por meio de uma avaliação dos respectivos sites institucionais. Esses indicadores estão alinhados às exigências da Lei de Acesso à Informação (LAI), da Lei de Responsabilidade Fiscal e a itens previstos na Constituição Federal. Com uma aplicação prática e objetiva, eles permitem um diagnóstico detalhado da qualidade da transparência legislativa, sendo possível aplicá-los a qualquer casa legislativa do país.

Diferentemente dos outros poderes, as iniciativas de participação e controle social nos órgãos do Sistema de Justiça são ainda tímidas. Os mecanismos de transparência ativa estão implementados apenas de maneira satisfatória. Ainda são poucos os instrumentos que permitem interagir efetivamente com o Poder Judiciário, cabendo à participação e o controle social um papel muito reduzido, muito aquém aquele que as ferramentas das tecnologias de informação poderiam hoje proporcionar. 


\section{CONCLUSÕES}

A crescente complexidade da sociedade contemporânea tem feito a participação do Poder Judiciário e das outras instituições do Sistema de Justiça em decisões políticas do Estado algo inevitável. À medida que leis e normas abrangem os mais diversos aspectos da vida política e social e as competências do Ministério Público e da Defensoria Pública são ampliadas, o Sistema de Justiça acaba tendo sua influência cada vez mais ampliada no regime democrático.

Na concepção moderna de política pública, a participação e o controle social são elementos que fortalecem a democracia e criam canais institucionais para dar vazão à conflitividade social. Um Estado transparente e permeável à participação tende a se tornar mais resistente à corrupção, ao tráfico de influência e outros tipos de desvios. A introdução de elementos de participação e controle social apoiado no uso das TICs poderia promover o Judiciário a um grau mais alto de transparência, accountability social e legitimidade democrática.

O controle da sociedade sobre as atividades do Sistema de Justiça envolve não somente o acesso à informação de suas instâncias e instituições, mas também graus maiores de consulta e participação social nos processos de elaboração de políticas e decisórios relacionados à administração, regulação e fiscalização de seus órgãos. Essas múltiplas dimensões do controle social ainda são bastante frágeis quando consideradas as principais instituições do Sistema de Justiça. A forma como se dá a escolha de membros dos tribunais superiores do Poder Judiciário, sem consultas à sociedade e sem usar quaisquer canais de comunicação digital, é um exemplo disso. A inexistência de registros públicos acerca do processo de tomada de decisão para a escolha de ministros - com o caso citado do STF - é grave sintoma.

Se, por um lado, a participação social para estabelecer objetivos de longo prazo e prioridades políticas nas instituições políticas e no próprio Judiciário se realiza predominantemente de maneira presencial - por meio de Audiências Públicas, Orçamento Participativo, Conselhos de Direitos, Conferências Nacionais -, por outro, essa participação só é possível em um ambiente de grande abertura de dados e informações sobre as Políticas 
Públicas de que se quer participar, o que se dá predominantemente de maneira eletrônica e virtual. Assim, acesso à informação, accountability e participação social estão intimamente ligados. O quadro de crescimento do papel do Judiciário na vida pública brasileira em tempos recentes demanda um maior nível de accountability que só pode ser feito com a existência de registros e a possibilidade de controle social, que hoje se dá principalmente por meios digitais. Ao permitir que procedimentos como esse fiquem fora do accountability, há risco de perda de credibilidade do governo, assim como das decisões do órgão superior, abrindo-se espaço a crises institucionais, fragilizando-se ainda mais a democracia.

Cabe dizer que enquanto desenvolvem-se de modernos instrumentos de transparência ativa por meios digitais, subsistem problemas básicos no atendimento direto nos fóruns e cartórios, ainda carentes de um bem estruturado serviço ao cidadão. A realidade dos fóruns, em especial das justiças estaduais, revela problemas como a longa espera nos cartórios forenses; as altas taxas cobradas por simples cópias de documentos; restrições no atendimento a cidadãos (seja por horários reduzidos ou por falta de pessoal); recusa de juízes em atender advogados; impossibilidade de acesso às audiências das varas criminais; falta de acessibilidade para pessoas com deficiência às salas de audiências; condições gerais de infraestrutura impróprias (como instalações elétricas ou hidráulicas em péssimo estado: salas de esperas pequenas e/ou com bancos quebrados). Isso constitui um conjunto de problemas que afetam muito a qualidade da prestação jurisdicional e que contrastam também com os altos salários, auxílio-moradias e outros penduricalhos recebidos por juízes. Talvez esses problemas tivessem sido equacionados se o Sistema de Justiça adotasse mecanismos de controle social, que incluíssem avaliação de serviços, fiscalização e a inclusão da população em suas políticas e planejamentos.

Os problemas no acesso à informação, a ausência na prática de controle externo baseado no controle social e as condições gerais de atendimento à população, tomados em seu conjunto, denotam um afastamento desse Poder da população e ao cidadão que deveria servir. Ouvidorias externas, a exemplo do modelo da Defensoria Pública de São Paulo, a realização de audiências públicas para ouvir a população e suas 
necessidades no acesso à Justiça, a permeabilidade da participação em casos socialmente sensíveis e relevantes - a exemplo do que já ocorre no STF - seriam medidas que ajudariam a diminuir esse afastamento.

Ao não se abrir ao controle social e à participação cidadã, e ainda ao ignorar as ferramentas tecnológicas que poderiam facilitar esse processo, o Judiciário acaba por se fechar sobre si mesmo. Distante da população e politizado no pior sentido da palavra, sua transparência passa a ser opaca, ao passo que a cidadania desestimulada. Cabe lembrar Bobbio (1977), que afirma que "o protagonista da sociedade democrática é o cidadão, o homem das ruas", não o especialista ou o perito. 0 revestimento de uma legitimidade tecnocrática por vezes oculta relações de interesses que passam a largo da cidadania.

A efetividade no cumprimento de suas missões institucionais depende de uma cultura mais aberta de acesso à informação, à participação social, ao controle social e à inovação tecnológica e social. Conforme afirmamos anteriormente, a transparência opaca envolve disseminação de informação que, na prática, não revela como as instituições funcionam e não garante que mecanismos de controle social possam funcionar. Já uma autêntica transparência diz respeito a práticas que revelam informação útil e confiável sobre o desempenho institucional, permitindo que cidadãos e sociedade civil exerçam um papel mais importante no accountability dessas instituições republicanas. Na democracia atual, os Direitos Civis e Políticos só podem ser garantidos através de um Sistema de Justiça que possa defendê-los. Nesse contexto, esse sistema precisa e deve ser fortalecido, incorporando novas tecnologias que possibilitem uma aproximação com a população.

\section{NOTAS}

1 A metodologia do CEJA avalia os sítios do CJF, o STJ, os cinco Tribunais Regionais Federais e ainda o da Justiça Federal de São Paulo.

2 Ver https://www25.senado.leg.br/web/atividade/materias/-/materia/107117

3 Ver http://www.participa.br/

4 Ver https://edemocracia.camara.leg.br/

5 Ver https://edemocracia.camara.leg.br/wikilegis/

6 Ver https://www12.senado.leg.br/ecidadania

7 Ver https://www12.senado.leg.br/transparencia/indice-de-transparencia-legislativa 


\section{REFERÊNCIAS}

BENEVIDES, Maria Victoria de M. A Cidadania Ativa: referendo, plebiscito e iniciativa popular. São Paulo: Editora Ática, 1991.

BOBBIO, Norberto. Que alternativas a la democracia representativa?. In El marxismo y el Estado. Barcelona: Editorial Avance, 1977.

CEJA (2017). IAcc - Índice de Accesibilidad a la Información Judicial en Internet 2017 ( $10^{\circ}$ Versión). Disponível em: http://biblioteca. cejamericas.org/bitstream/handle/2015/5549/IAcc_Decimaversion_2017. pdf?sequence=1\&isAllowed=y. Acesso em: 15 nov. 2018.

(2012) IAcc - Índice de Accesibilidad a la Información Judicial en Internet ( $8^{\circ}$ Versión), . Disponível em: http://www.cejamericas.org/portal/ index.php/es/component/content/article/995-presentacion-7o-version-delindice-de-accesibilidad-a-la-informacion-judicial-en-internet-iacc-. Acesso em: 15 nov. 2018.

CRAVEIRO, Gisele da Silva ; MACHADO, Jorge A. S.; ANGELICO, Fabiano ; MARTINS, Paula (2017) Desafios da transparência no sistema de justiça brasileiro. 2. ed. (com análise das entrevistas). COLAB: São Paulo. 199p. Online: http://www.forum-global.de/docs/Transparencia_no_Sistema_de_ Justica_do_Brasil_2ed_com_entrevistas.pdf . Acesso em: 15 nov. 2018.

FOX, Jonathan. The Uncertain Relationship between Transparency and Accountability. Development in Practice, v. 17, n. 4-5, p. 663-671, 2007. Disponível em: https://serval.unil.ch/resource/serval:BIB_E242DE5C0E09. P001/REF. Acesso em: 15 nov. 2018.

SEMER, Marcelo. Preservação do Juiz Natural. Associação Juízes para a Democracia, 2018. Disponível em: https://ajd.org.br/preservacao-do-juiznatural/. Acesso em: 18 dez. 2018.

SMITH, Rogers M. Modern Citizenship. In Isin, Engin F.; Turner, Bryan S.(eds.). Handbook of Citizenship Studies. London: Sage. pp. 89-104, 105. Disponível em: http://shora.tabriz.ir/Uploads/83/cms/user/File/657/E_ Book/Urban\%20Studies/HANDBOOK\%20of\%20CITIZENSH\%20P\%20 STUDIES.pdf . Acesso em: 15 nov. 2018. 
Recebido em: 26-11-2018

Aprovado em: 17-12-2018

\section{Jorge Machado}

Professor-associado. Curso Gestao de Polítcas Públicas, USP. E-mail: machado@ usp.br

\section{Gisele Craveiro}

Professora do curso Sistemas de Informacao (USP). E-mail: giselesc@usp.br

\section{Ester Rizzi}

Professora do curso Gestao de Políticas Públicas, USP. E-mail: ester.rizzi@usp.br Rua Largo de São Francisco, 95 - CEP: 01005-010 - São Paulo - SP 
